\title{
Filigrane
}

Écoutes psychothérapiques

\section{Argumentaire 2013 : Psychanalyse et temporalités}

\section{Le comité de rédaction}

Volume 20, numéro 2, automne 2011

URI : https://id.erudit.org/iderudit/1007617ar

DOI : https://doi.org/10.7202/1007617ar

Aller au sommaire du numéro

\section{Éditeur(s)}

Revue Santé mentale au Québec

ISSN

1192-1412 (imprimé)

1911-4656 (numérique)

Découvrir la revue

Citer ce document

Le comité de rédaction (2011). Argumentaire 2013 : Psychanalyse et temporalités. Filigrane, 20(2), 131-133. https://doi.org/10.7202/1007617ar d'utilisation que vous pouvez consulter en ligne.

https://apropos.erudit.org/fr/usagers/politique-dutilisation/ 


\section{Argumentaire 2013 : Psychanalyse et temporalités}

\section{Le comité de rédaction}

'inconscient est hors temps: la temporalité est abolie au cœur même de la découverte freudienne. Principale leçon de l'analyse: «le temps ne passe pas» nous rappelle Pontalis. Pourtant, sans être un concept purement psychanalytique, la temporalité s'immisce à chaque détour de l'expérience analytique. En témoigne le fait qu'à travers celle-ci, «la temporalité vectorisée du temps de la vie se remettra progressivement en place» (F. Guignard).

L'inconscient participe d'une mémoire particulièrement vivante, active, porteuse d'un héritage, qui marque chaque instant du parcours de chacun. Autre temporalité, donc, que celle à laquelle se réfère la psychanalyse, telle que le dévoile la notion fondamentale d'après-coup: une "frappe » qui surgit dans le présent, qui est issue d'un passé toujours actif et qui émerge dans la dynamique transférentielle surprenant les deux protagonistes, tant l'analyste que l'analysant.

En outre, si la psychanalyse s'est depuis longtemps intéressée aux notions de traumatisme et d'agir, n'est-ce pas encore en ce lieu, celui du passé toujours actuel, hors symbolisation, qui évite la parole et la représentation de mot au profit d'autres voies d'expression - que le psychanalyste sera encore aujourd'hui particulièrement pris au dépourvu? Que son travail de mise en mots se trouvera parfois déjoué, voire même, mis en hors jeu?

Dans la cure psychanalytique peut se déployer une nouvelle temporalité: la temporalité psychique qui fait fi du temps chronologique. L'analysant y est invité à retrouver le temps d'hier, celui d'autrefois resté intact. La régression est ici de mise, soutenue par le travail analytique, à condition que l'analysant puisse s'y abandonner, l'espace d'une séance, d'une semaine, au fil des mois, voire des années... Il découvre alors la force d'un désir qui traverse le temps. Les patients d'aujourd'hui sont-ils prêts à prendre ce risque? N'y a-t-il pas contradiction avec l'accent mis sur le présent, sur le temps accéléré que soustendent les nouvelles technologies, et sur la course en avant de la vie postmoderne, voire hypermoderne, pour se permettre ce retour vers le passé, 
vers l'héritage, pour tolérer une mise entre parenthèses volontaire du mouvement effréné de la réalité? L'analyste accepte d'être amené au fil des séances en un nouveau lieu circonscrit par la répétition transférentielle. Il partage de plein gré cet espace-temps avec l'analysant, mais à quelles conditions? à quel prix?

Nous le savons, les notions de temps et d'espace sont étroitement imbriquées. Encore aujourd'hui, la référence psychanalytique prend place à l'extérieur du cadre traditionnel de la cure: dans les hôpitaux, les universités, et autres institutions, mais aussi dans certains milieux communautaires. En ces lieux, le rapport au temps est sans cesse remis en question : rencontres ponctuelles avec des sujets en crise, suivis de quelques séances avec des adolescents toujours online ou avec des enfants dont les parents sont impatients de retrouver le rythme normal, limitation administrative de la durée des suivis, etc. En acceptant cette implication «hors les murs », à l'extérieur de son cabinet, le psychanalyste est confronté aux exigences simultanées d'une double temporalité, celle du psychisme et celle de la réalité externe. Lorsque le travail du clinicien est déporté sur cette scène externe qui « exige» des résultats rapides, suivant en cela la pression d'une souffrance actuelle et des contraintes de la société, il semble que la temporalité du monde interne et de sa mise en récit soit, au moins partiellement exclue, à tout le moins suspendue. Le travail analytique s'en trouvera-t-il simplement modulé, ou complètement inaccessible? Autre temps, autres mours, dit-on...

Autres mœurs au point qu'un savoir jadis considéré comme quasi immuable, pourrait, en moins d'un siècle, être fondamentalement remanié. En effet, la théorie du développement psychique paraît aujourd'hui sens dessus dessous. Première cible de ce bouleversement: la référence à une phase de latence, désormais questionnée. En effet, qu’arrive-t-il de ce répit dans la tumulte des remaniements pulsionnels, dès lors que les enfants et possiblement leurs parents ne peuvent résister à l'attrait de la pré-adolescence? Mais aussi, n'a-t-on pas affaire à un télescopage de la ligne du temps lorsque l'adolescence se prolonge et que les adultes perpétuent leur jeunesse dans leur corps et leurs comportements? Que dire d'une vieillesse qui devient de plus en plus tardive? Assistera-t-on à la création d'un "cinquième âge » (et que penser de ces stades sans nom?), alors que l'âge de la mort est sans cesse repoussé ? À se demander si le sujet humain trouve encore le temps d'appréhender la mort, et de penser la finitude de la vie pour enfin se permettre de vivre plutôt que de livrer une lutte sans merci pour sa survie. En ce sens, une hypothétique et apparente victoire de la pulsion de vie pourrait bien camou- 
fler une astuce de la pulsion de mort, alors que ce temps-bonus serait moins propice à une poursuite de l'évolution que prétexte à une stérile répétition. Freud découvrait par le corps des hystériques une souffrance, un langage passionnel tissé de souvenirs muets et pourtant combien tapageurs et envahissants. La psychanalyse allait naître et changer dès lors notre conception de la mémoire et de l'histoire tant individuelle que collective. Nous n'en avons sans doute pas encore mesuré toute la portée.

Date de tombée des textes: $1^{\text {er }}$ septembre 2012

Informations pour les auteurs: www.revuefiligrane.ca 